\title{
Closed-loop ring resonator topology for bandpass filter applications
}

\author{
Norfishah Ab Wahab, M. N. Md Tan, M. N. Hushim \\ Faculty of Electrical Engineering, Universiti Teknology MARA, Shah Alam, Selangor, Malaysia
}

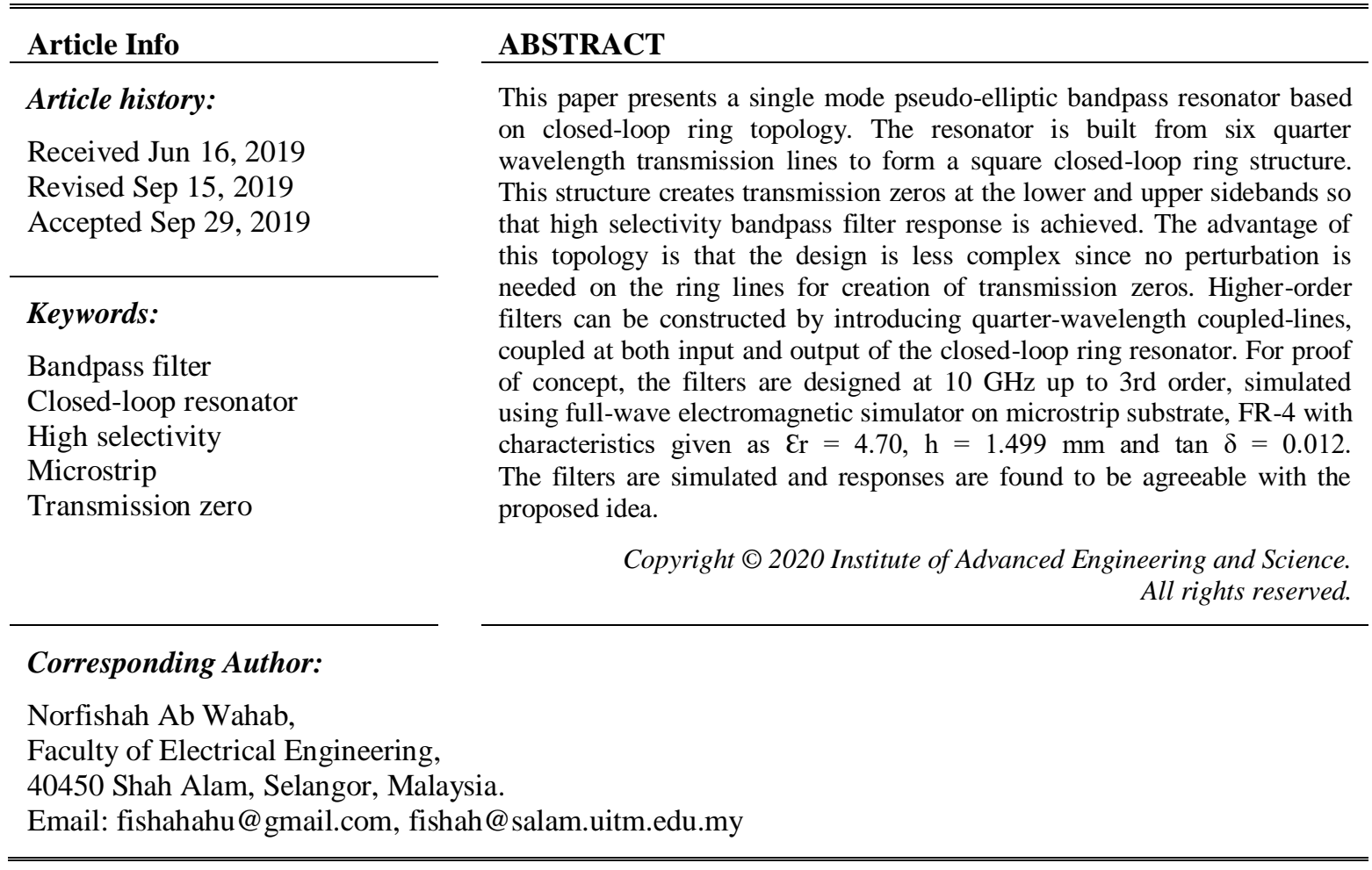

\section{INTRODUCTION}

Bandpass filters are indispensable components in $\mathrm{RF} /$ microwave wireless communication systems [1-5]. Filter is a device that commonly used in telecommunication system. Besides, it also used in radar system. The main function of the filter is to pass the desired frequency band and block those unwanted signal frequencies. In recent years, demand for a low, cost, low loss, and compact size filters arises rapidly. Thus, microstrip band pass filters are becoming more popular because of their low cost and easy to fabricate [6-9].

Until to-date, numerous designs of microstrip filters had been proposed. These filter designs were developed using various method and technologies depending on applications [10-14]. Besides, the response and performance of filters can also be improved by modification of structures or by selection of high performance substrate [15-18].

It is well-known a ring topology may produce high performance bandpass filter with high selectivity [19-23]. Hence, in this work, a single square ring resonator is introduced as a base cell which employs quarter-wavelength coupled-lines, coupled at the input and output of the ring lines. By doing so, higher order filters are created. The response showed the existence of transmission zeros at lower and upper side bands for high selectivity [24-26]. The advantage of this topology is that, transmission zeros are maintain, while increment of numbers of orders are increased by introducing more coupled lines This characteristic is important for high performance of bandpass filter especially when this filter is working at higher frequency above $10 \mathrm{GHz}$. In terms of its application, these filters are suitable for systems using X-Band frequency range. 


\section{RESEARCH METHOD}

Figure 1 below shows a common structure of filter line on microstrip substrate. There is a conducting line with certain width and thickness that are printed on the top of substrate. The bottom of the substrate is a ground plane. The line and the ground plane are usually made of conducting material, like copper [8]. The line is used to deliver an electromagnetic wave from input port to output port. Bend in filter design is a part of microstrip discontinuities. There are four types of bending which are $45^{\circ}$ mitered, the $90^{\circ}$ bend, the inner cut-off and the outer cut-off [25]. It is usually used to get a better value of the return loss and the insertion loss [8].

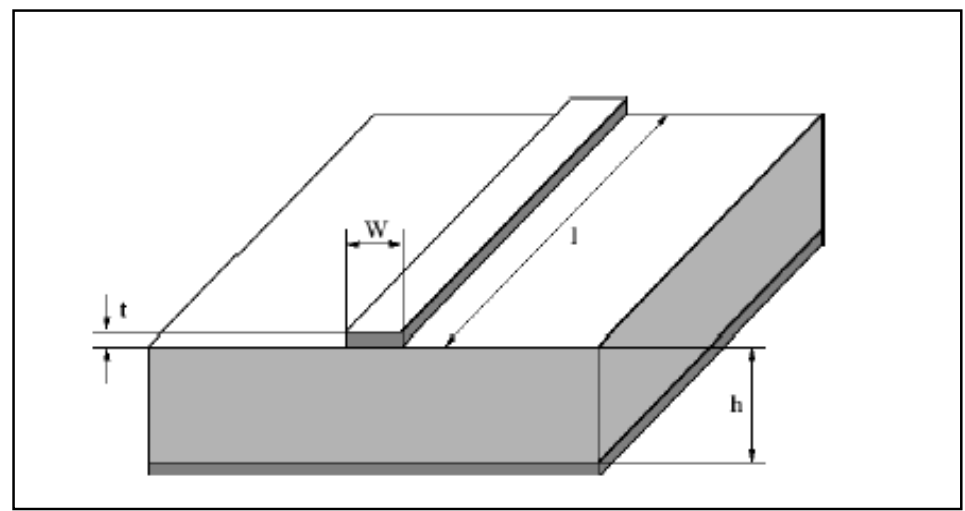

Figure 1. Microstrip filter specifications

Based on these findings, the proposed designs are carried out. The performance of the resonators is measured using Scattering Parameters which are insertion loss, return loss, fractional bandwidth and transmission zero. The proposed designs are simulated using electromagnetic simulator software at $10 \mathrm{GHz}$ using microstrip technology on FR-4 substrate with the properties tabulated in Table 1. Figure 2 illustrates the basic resonator proposed in this work.

Table 1. Substrate Properties of FR-4

\begin{tabular}{cc}
\hline Parameters & Values \\
\hline Dielectric constant & 4.7 \\
Magnetic constant & 1.0 \\
Loss Tangent & 0.012 \\
Resistivity & 1.0 \\
Metal Thickness & $0.036 \mathrm{~mm}$ \\
Metal Roughness & $1.397 \mathrm{e}^{-3} \mathrm{~mm}$ \\
Height of the substrate & $1.499 \mathrm{~mm}$ \\
\hline
\end{tabular}

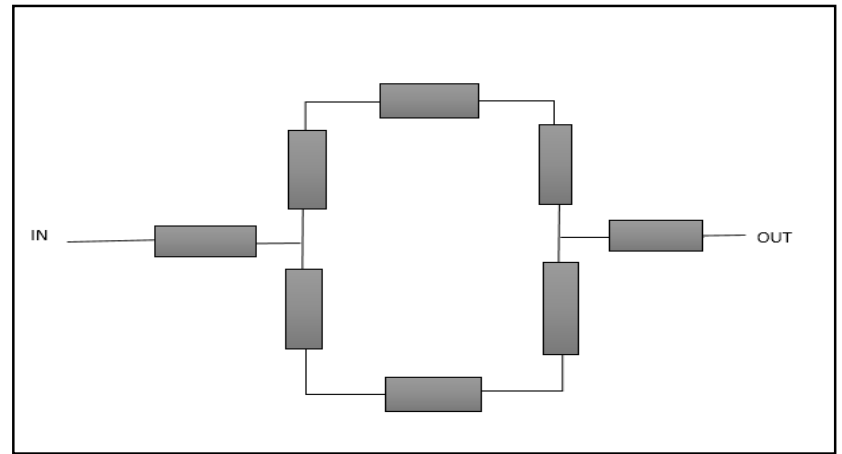

Figure 2. Closed loop resonator topology

This resonator is built for bandpass filter application. The topology is based on the closed loop structure to create a square ring. As can be seen, the closed loop or ring topology is built on six quarterwavelength transmission lines resulting to one-and-a-half wavelength resonator. The advantage of this configuration is that it's compactness in design. The filter is designed at $10 \mathrm{GHz}$. When simulated, it shows pseudo-elliptic responses of single resonance bandpass with two transmission zeros at the stopbands. As shown in Figure 3, the value of return loss and insertion loss are $6.739 \mathrm{~dB}$ and $2.924 \mathrm{~dB}$ respectively. These results to poor performance because it does not achieve good filter design specification as required for bandpass filter application. Thus, some modification is introduced to improve the response. This is achieved by introducing two additional quarter wavelength coupled lines for creation of additional resonance and two quarter wavelength transmission lines at the input and output of the ring lines as shown Figure 4. By adding 
two additional quarter wavelength, the design is now having additional of half wavelength resonator resulting to an additional of resonance. Also, the presence of transmission lines at the input and output has improved the impedance matching of the resonator.

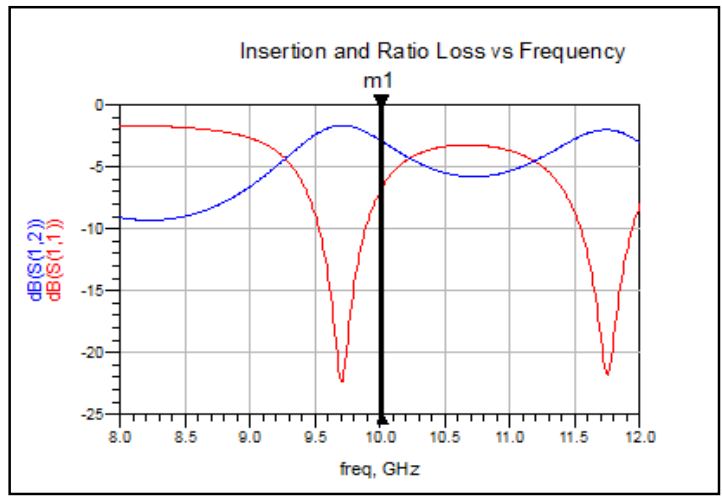

Figure 3. Response of bandpass filter for closedloop resonator

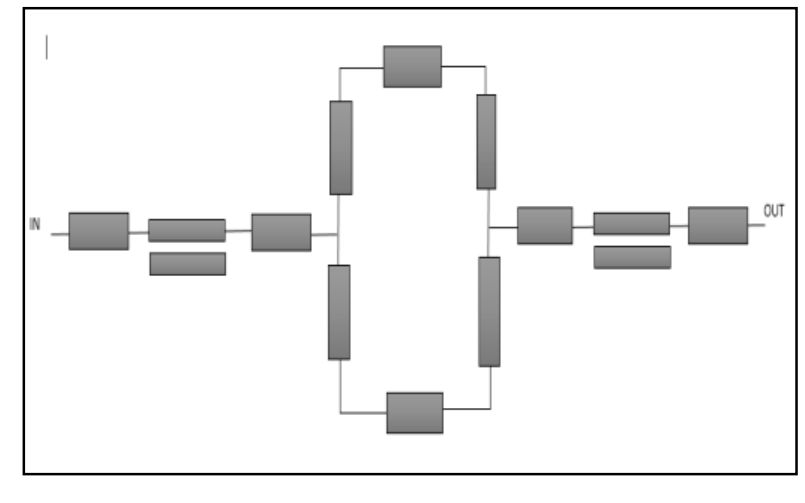

Figure 4. Two coupled-lines with closed-loop resonator

To further explore the possibilities of creating higher order filter, the basic cell is now added with one more quarter wave length coupled line at the output of the ring lines as shown in Figure 5. With the presence of additional coupled-line has created half wavelength resonator. These two newly proposed designs are designed at $10 \mathrm{GHz}$ and simulated to observe the responses.

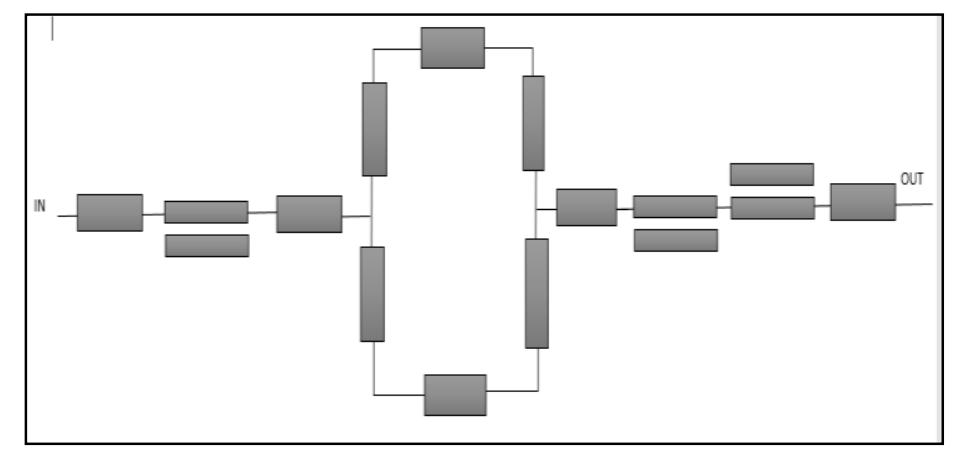

Figure 5. Three coupled-lines with closed loop resonator

\section{RESULTS AND ANALYSIS}

In this section, the simulated results of the two newly proposed resonators are presented. In Figure 6, two resonances are found at frequency $9.680 \mathrm{GHz}$ and $10.95 \mathrm{GHz}$. The return loss is attenuated at $21.593 \mathrm{~dB}$ while insertion loss is found at $3.719 \mathrm{~dB}$. There are two transmissions zeros, found at the lower and upped side band of the response to give high selectivity bandpass filter response.

In Figure 7, the response of the filter shows three resonances with four transmission zeros. At 10 $\mathrm{GHz}$, the return loss, $\mathrm{S} 11$ attenuated at $18.095 \mathrm{~dB}$ while insertion loss, $\mathrm{S} 12$ is $2.706 \mathrm{~dB}$. The four transmissions zeros are found at $8.12 \mathrm{GHz}, 9.360 \mathrm{GHz}, 11.46 \mathrm{GHz}$ and $11.88 \mathrm{GHz}$. From both simulations it can be seen that by adding coupled lines create more resonance and at the same time the additional of transmissions lines improve the impedance matching. The formation of transmission zeros at the lower and upper stopbands improve the selectivity of the bandpass responses. 


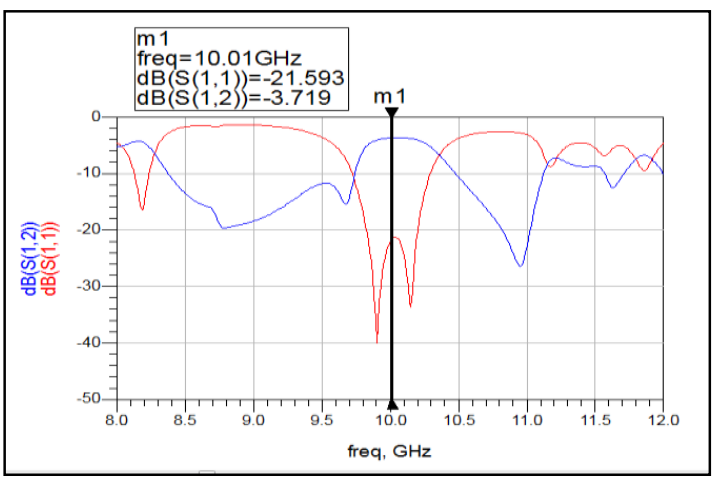

Figure 6. Response of the S-parameters for two coupled-lines with closed loop resonator

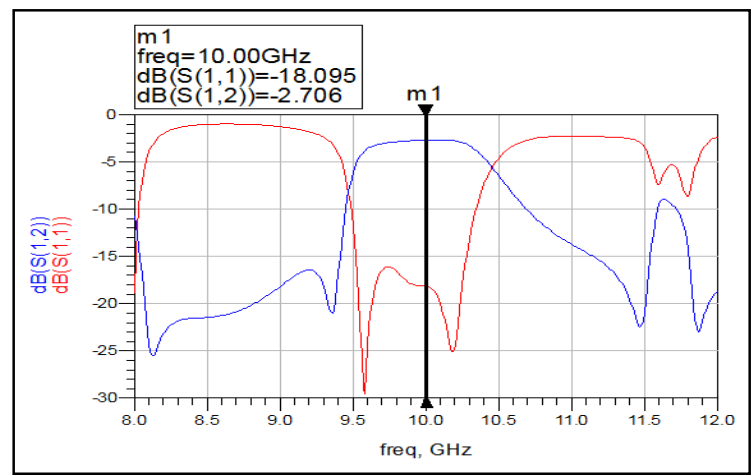

Figure 7. Response of the S-parameters for three coupled-lines with closed loop resonator

\section{CONCLUSION}

A single closed loop resonator topology was presented. Based on this concept, quarter wavelength coupled lines is introduced to create higher order filter. Quarter wavelength transmission lines are introduced in the ring structure to create for impedance matching and improve in band response. The designs were designed at $10 \mathrm{GHz}$, simulated using full wave electromagnetic simulator and the results were observed. The results showed good performance of resonators for in terms of insertion losses and return losses. Finally, these resonators can be further explored for higher frequency spectrum. To conclude the work, these proposed resonators are suitable for bandpass filter applications that require high selectivity

\section{ACKNOWLEDGEMENTS}

This work was supported by the Ministry of Education Malaysia, under Niche Research Grant Scheme (NRGS) [600-RMI/NRGS 5/3 (3/2013)] and the Faculty of Electrical Engineering, Universiti Teknologi MARA (UiTM), Shah Alam, Malaysia

\section{REFERENCES}

[1] J., He, K., Gao, Z., Shao, "A Novel Compact Ka-Band High-rejection Diplexer Based on Substrate Integrated Waveguide," Computational Problem-Solving (ICCP), 2012 International Conference, pp.193-197, 2012.

[2] Z., Kordiboroujeni and Jens Bornemann, "Mode Matching Design of Substrate Integrated Waveguide Diplexers," Microwave Symposium Digest (IMS), 2013 IEEE MTT-S International.

[3] Xiaoke Yi, Robert A. Minasian," New Spectrum-Sliced Microwave Photonic Filter for High-Frequency Signal Processing", IEEE Photon. Technol. Lett. 21(4), 230-232, 2009.

[4] K. Gong, W. Hong, Y. Zhang, P. Chen and C. J. You," Substrate Integrated Waveguide Quasi-Elliptic Filters with Controllable Electric and Magnetic Mixed Coupling," IEEE Transactions on Microwave Theory and Techniques, vol. 60, no. 10, pp. 3071-3078, Oct. 2012.

[5] Yuan Yu, Jianji Dong, Xiang Li, Lina Zhou, and Xinliang Zhang,"Optical microwave photonic filter with bandpass and notch filtering shapes," Asia Communications and Photonics Conference and Exhibition, Dec. 2010.

[6] J. S., Hong, "Microstrip Filters for RF Microwave Application," 2rd ed., John Wiley n Sons, 2011.

[7] M. S., Razalli, A., Ismail, and M. A., Mahdi, "Novel compact microstrip ultra-wideband filter ultilizing shortcircuited stubs with less vias," PIER 88, pp 91-104, 2008.

[8] J.S., Hong, M. J., Lancaster,"Bandpass characteristics of new dual-mode microstrip square loop resonators," Electronics Letters, Vol. 31, No. 11, 891-892, 1995.

[9] Tahereh Beiki and Mirshahram Hosseinipanah, "Harmonic suppression in short-circuited stub bandpass filter by means of a new miniaturized bandstop filter", Analog Integrated Circuits and Signal Processing, 10.1007/s10470018-1230-5, 96, 3, (589-596), (2018).

[10] W., Qin, Q., Xue, "Design of a Planar Diplexer Based on Complementary Compact Microstrip Resonant Cell," Microwave Conference Proceedings (APMC), 2012 Asia-Pacific pp. 526-528.

[11] S.W., Fok, P., Cheong, K.W., Tam, R. P., Martins, "A novel microstrip square-loop dual-mode bandpass filter with simultaneous size reduction and spurious response suppression," IEEE Transactions on Microwave Theory and Techniques, pp 2033-2041, 2006.

[12] J. C., Liu, F. S., Huang, C.P., Kuei, "Quad-band dual-mode resonator with dual-square Loop for WLAN and WiMAX systems," CSQRWC, pp 100-103, 2012.

[13] Martin F., "Artificial Transmission Lines for RF and Microwave Applications", 1st ed. New York: Wiley; 2015. 
[14] P. B., Saha, S., Roy, M., "Bhowmilk. Improvement of Parallel Coupled Bandpass Filter Using Coupled Closed Loop Square Resonator Structure," $2^{\text {nd }}$ International Conference on Signal Processing and Intergrated Networks(SPIN), 2015.

[15] Muhajir Mustapa, ZahrilAdha Zakaria, Noor Azwan Shairi,"Design of Quasi-Elliptic Bandpass Filter for Substrate Integrated Waveguide (SIW) Using Cross Coupling Technique," Indonesian Journal of Electrical Engineering and Computer Science (IJEECS), vol. 12, No. 3, December 2018, pp. 1366-1372.

[16] Tao Zou, Bo Zhang, Yong Fan, "Design of a 73GHz Waveguide Bandpass Filter", 2016 IEEE 9th UK-EuropeChina Workshop on Millimetre Waves and Terahertz Technologies (UCMMT).

[17] W-K Lee, H-Y Hwang," Size and harmonic reduced Wilkinson balun using parallel coupled line with open stub", Electromagn Eng Sci., 2014;14:387-392.

[18] G. Zhang, J. Wang, J. Pan and H. Gu, "Compact $60 \mathrm{GHz}$ LTCC balun bandpass filter with two transmission zeroes," Electronics Letters, vol. 51, no. 8, pp. 637-638, 1642015.

[19] H. Y. Sim K-S, Hwang, “ UWB harmonic-suppressed miniaturized ring bandpass filter using artificial transmission lines”, Microw Opt Technol Lett. 2017;59: 2493-2497.

[20] J. U. Martinez, B. F. Resendiz, "Second harmonic suppression band-pass filter based on a modified 1st order microstrip coupled line", Microwave Conference (LAMC), IEEE MTT-S Latin America. IEEE, Dec. 2016.

[21] T. G. Abouelnaga, T. G., A. S. Mohra, "Novel compact harmonic-rejected ring resonator based bandpass filter", Progress in Electromagnetic Researches C, 74, 191-201,2017.

[22] K. S. Sim, H. Y. Hwang, "UWB harmonic-suppressed miniaturized ring bandpass filter using artificial transmission lines", Microwave and Optical Technology Letters, 59,2493-2497.

[23] Furqan Furqan, Said Attamimi, Andi Adriansyah, Mudrik Alaydrus, "Bandpass filter based on complementary split ring resonators at X-Band," Indonesian Journal of Electrical Engineering and Computer Science (IJEECS), vol. 13, No. 1, January 2019, pp. 243-248

[24] N. A., Wahab, A., Amiruddin, R., Khadijah, Z., Mat Yasin, N. A., Salim, N. A., Rahmat, N. F. A. Aziz, "Bandpass filter based on ring resonator at RF frequency above $20 \mathrm{GHz}$," Indonesian Journal of Electrical Engineering and Computer Science (IJEECS), 2018.

[25] S. K. M., Khanfar, M. K. M., Salleh, Z. I., Khan, Z., Awang, "Microwave Ring Resonator with a QuarterWavelength Coupled-line Integration," IEEE Symposium on Wireless Technology and Applications (ISWTA), 2012.

[26] N. A., Wahab, Mohd K. M., Salleh, Sameh K. M., Khanfar, Zuhani I., Khan, and Z., Awang, "Synthesis of a single side access ring resonator for higher order bandpass filters," Progress in Electromagnetics Research Letters, vol. 38, 137-150, pp. 137-150, 2013.

\section{BIOGRAPHIES OF AUTHORS}

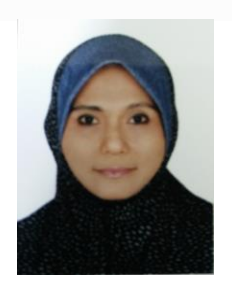

Norfishah Ab Wahab was born in Malaysia, in 1963. She received the degree in Electronics Engineering from Universiti Teknologi MARA (UiTM), Malaysia, MSc in Telecommunication and Information Engineering and $\mathrm{PhD}$ in microwaves, electromagnetism in the same university. Currently, she is a senior lecturer in Faculty of Electrical Engineering, UiTM Shah Alam, Malaysia. She has been working in UiTM since April 2008. From 1992 to 2004, she was employed by Telekom Malaysia. She worked in various divisions such as microwave, fiber cable and network system departments. Her major research areas are in microwave and electromagnetic modeling, low-powered electronic design, energy harvesting and efficiency.

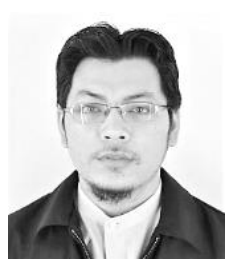

Mohd Nasiruddin Hushim was born in Kuala Lumpur, Malaysia, on February 25, 1982. He received the degree of bachelor in Electrical Engineering from Kolej Universiti Teknologi Tun Hussein Onn, Johor, Malaysia in 2005 and degree of master in Technical and Vocational Education from Universiti Tun Hussein Onn, Johor, Malaysia in 2007. He is currently working toward the Ph.D degree in Electrical Engineering at the Universiti Teknologi Mara Shah Alam, Selangor, Malaysia. His research principally concerns the design of passive microwave design.

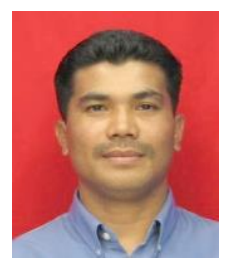

Mohd Nor Md Tan was born on August 14th, 1970 in Melaka, Malaysia. He received his Diploma in Electrical Eng (ELECT) Engineering from the Institut Teknologi Mara, Selangor, Malaysia in 1992. He received his B.Eng (Honours) Electronics and Electrical Engineering, in field of Communication from the University of Leeds, Leeds, UK in 1995. He completed his Master of Science in Radio Frequency Communications Engineering from the University of Bradford, Bradford, UK in 2002. Currently, he is a Senior Lecturer of Communication Department, Faculty of Electrical Engineering UiTM, Shah Alam, Selangor. His research interests are Radio Propagation, Antenna and RF design. His current focus is on his research activity, internal audit committee of Faculty and supervising Undergraduate students. 